\title{
Reliability Testing of a Nutrition Acuity Score (NAS) Tool
}

Jan Chan MRSc RD ${ }^{1,4}$, Liz da Silva MS RD2,4, Treeva Elliott RD³, Delara Saran MS RD2, Kristina Vandop RD²

${ }^{1}$ Fraser Health Authority, New Westminster, BC, ${ }^{2}$ Fraser Health Authority, Surrey, BC, ${ }^{3}$ Fraser Health Authority, Langley, BC,

${ }^{4}$ Clinical Instructor, Faculty of Land and Food Systems, University of British Columbia

\section{Introduction}

Dietetics lacks a nutrition acuity tool that categorizes inpatients based on nutrition diagnosis. This instrument (NAS) ranks nutrition diagnoses based on the need for medical nutrition therapy. It is organized in a four-point scale according to nutrition diagnosis domains and was content validated with a sample of Canadian dietitians.

\section{Objective}

To measure NAS inter-rater reliability when applied to inpatients.

\section{Methods}

- Dietitian raters required to have a minimum of 1 year of experience in a variety of practice areas in acute care.

- Trained concurrently using simulated cases

- Cases reflect a variety of patient types and were previously tested with experienced staff.

- Patients selected randomly.

- Raters prospectively assessed same inpatients independently.

- Inpatient assignment to raters was random.

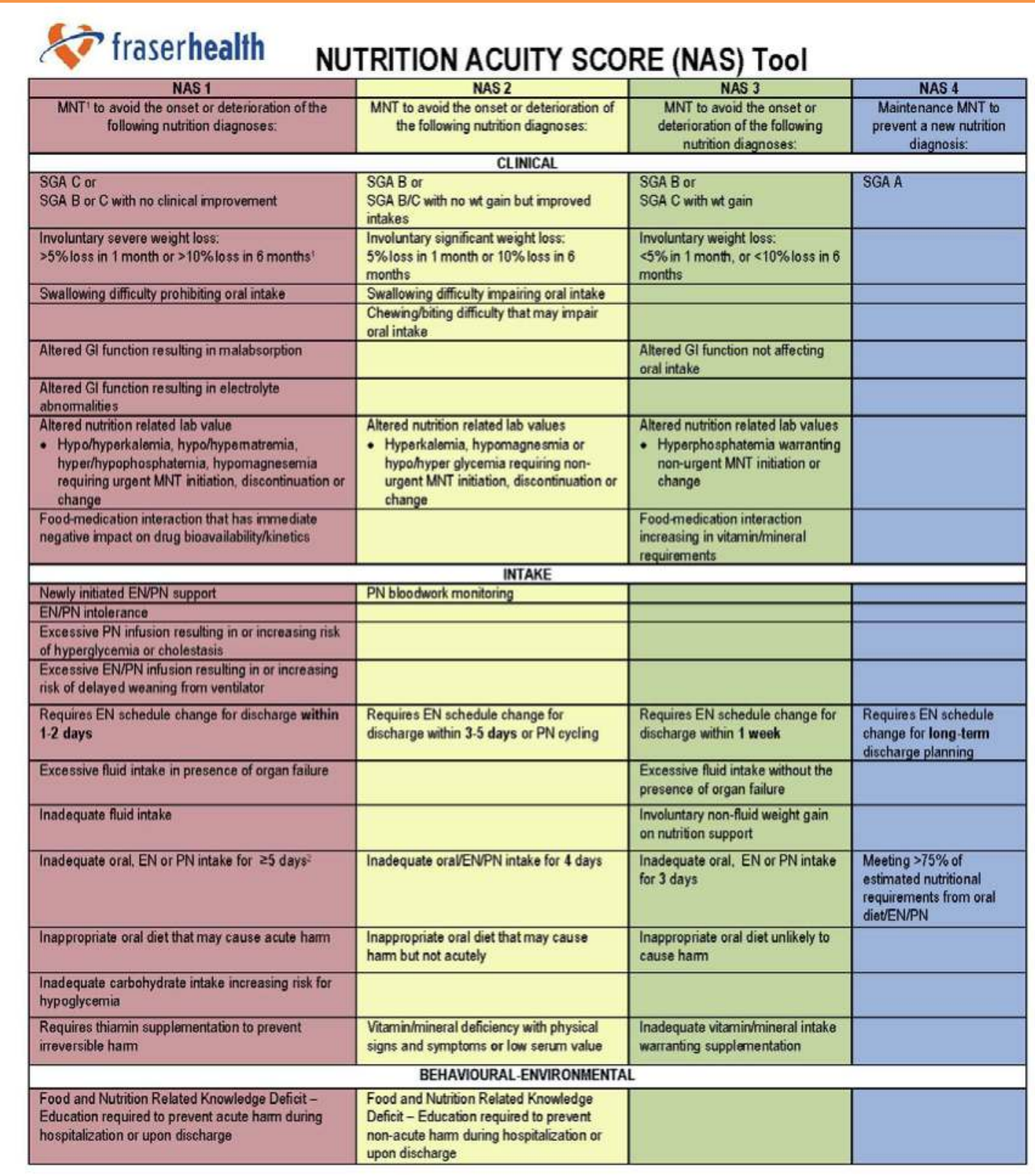

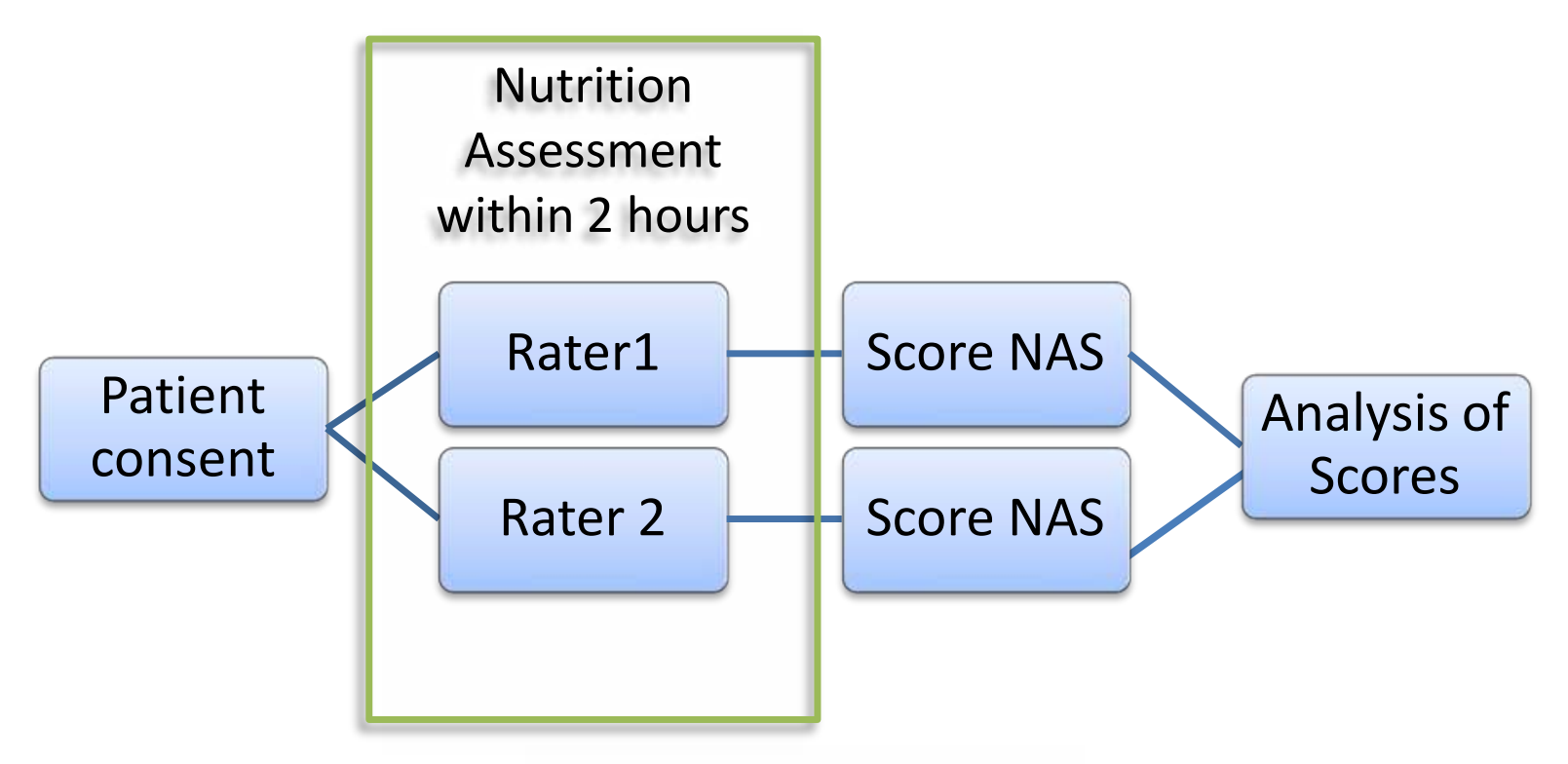

\section{Results}

Raters were female with 1 year of work experience. Inpatients ( $\mathrm{N}=41$ ) were from surgical or medical wards in a teaching hospital, $64.3 \%$ male ( $n=26)$, averaged 62 years (SD 14.9, 64-85 years) and 24 days from admission to NAS assignment (SD 34 days). Agreement between raters was 0.52 (linear weighted kappa). Raters felt agreement could have improved with changes to their training rather than the tool itself.

\begin{tabular}{|l|c|r|r|r|r|}
\hline $\begin{array}{l}\text { Raters NAS Score Cross Tabulation } \\
\text { N= 41 Patients }\end{array}$ & \multicolumn{4}{|l|}{ NAS Score Assigned by Rater2 } \\
\hline & $\begin{array}{c}\text { NAS } \\
\text { Scores }\end{array}$ & 1.0 & 2.0 & 3.0 & 4.0 \\
\hline & 1.0 & 12 & 7 & 2 & 0 \\
\cline { 2 - 7 } & 2.0 & 2 & 5 & 1 & 1 \\
\cline { 2 - 7 } & 3.0 & 0 & 0 & 2 & 0 \\
\cline { 2 - 7 } & 4.0 & 1 & 2 & 1 & 5 \\
\hline
\end{tabular}

\section{Conclusion}

The NAS was found to be moderately reliable. Reliability may improve if raters were trained using actual patients rather than simulated cases. Further research is required for confirmation.

\section{Significance to the Field of Dietetics}

With rising inpatient acuity and complexity of care, dietitians need a validated metric to describe and monitor their patients' nutrition acuity and advocate for resources. Study Funded by: Fraser Health, Strategic Imperatives Grant 